\title{
Sex Differences in Empathy and Its Relation to Juvenile Offending
}

\author{
Lisa Broidy \\ University of New Mexico, Albuquerque \\ Elizabeth Cauffman \\ University of Pittsburgh, PA \\ Dorothy L. Espelage \\ University of Illinois \\ Champaign-Urbana, IL \\ Paul Mazerolle \\ The University of Queensland, Australia \\ Alex Piquero \\ University of Florida, Gainesville
}

\begin{abstract}
Implicit in most theoretical accounts of sex differences in offending is the assumption that females are less likely than males to engage in crime-especially serious, violent crimein part because of their comparatively higher levels of concern for others and stronger affiliative ties. Much research suggests that significant sex differences in both empathy and serious offending emerge in adolescence, with females displaying notably higher levels of empathy and males engaging in notably higher levels of serious offending. However, there has been little empirical work assessing the degree to which sex differences in empathy among adolescents can account for sex differences in offending. This research uses data from a sample of adolescents attending public high schools in Philadelphia $(n=425)$ and a sample of adolescents incarcerated in the California Youth Authority (CYA) $(n=232)$ to examine the relation between empathy and serious offending. Results suggest that empathy acts as a protective factor for both males and females but that there are subtle differences among males and females in the relation between empathy and offending.
\end{abstract}

Keywords: juvenile offenders; empathy; adolescents; gender

0 ex is among the strongest correlates of criminal offending. Males offend at significantly higher rates than females and these sex differences are especially pronounced with respect to serious, violent crime (Chesney-Lind \& Sheldon, 1998; Kruttschnitt, 1994; Steffensmeier \& Allen, 1996). In recent decades, a growing body of theoretical and empirical work has attempted to explain the factors that might account for both similarities and differences in the offending patterns of males and females (see Steffensmeier \& Broidy, 2000, for a review). One undertheorized and understudied (but commonly 
invoked) explanation for females' comparatively limited involvement in serious and violent offending is their greater tendency toward empathy. That is, females are considered to be less inclined toward violent offending because they are more empathic than males and, as such, are more inclined to think about the direct and indirect effects of their behavior on others, especially those they are close to (Naffine, 1987; Pollock, 1999; Simpson, 1989; Steffensmeier \& Allen, 1996). Sex differences in both offending and empathic behaviors are well documented, and these differences appear to be especially acute in adolescence. However, there has been little empirical work examining whether empathy is a factor that contributes to sex differences in offending among male and female adolescents. This research represents an initial step toward testing the relation between empathy and juvenile offending by assessing similarities and differences in emotional and behavioral manifestations of empathy across adolescent male and female offender and high school samples.

\section{Empathy and Offending}

Empathy is commonly described as an affective response to the emotional state of another, involving the vicarious matching of another's emotions and/or concern for another's emotional well-being (Eisenberg, 2000; Eisenberg \& Miller, 1987; Mehrabian \& Epstein, 1972; Underwood \& Moore, 1982). Empathic responses evolve out of interactions between affective and cognitive emotional processes (Cohen \& Strayer, 1996). The affective component of empathy refers to emotions an individual experiences in response to another's affective state (Feshbach, 1975). The cognitive component refers to the process of understanding the emotions of another via association or perspective taking (Hoffman, 1977). Manifestations of empathy, then, involve thoughts and/or actions that reflect a concern for the feelings and/or general well-being of another/others, typically resulting in supportive and prosocial emotional or behavioral responses with seemingly altruistic motives (Batson \& Coke, 1981; Eisenberg \& Miller, 1987). Here we focus on two potential manifestations of empathy-emotional empathy and behavioral empathy. Emotional empathy refers to the degree to which an individual considers the consequences of his or her behavior for the feelings and/or general well-being of another/others. Behavioral empathy refers to the degree to which an individual engages in specific actions for the express benefit of others.

In recent decades, theory and research in psychology have highlighted the importance of empathy with respect to moral development. Such work suggests that, along with the development of rational thought and related social-cognitive skills (Kohlberg, 1976), affective processes rooted in empathic responses to the emotional experiences of others are also central to moral development (Eisenberg \& Miller, 1987). In fact, empathy has been described as a "moral emotion" because of its fundamental role in the development of morality (Eisenberg, 2000). Moreover, deficits in the capacity to respond to others with empathic emotions or behaviors, appear to be linked to various antisocial behaviors and externalizing psychopathologies, including aggression and conduct disorder (Cohen \& Strayer, 1996; Miller \& Eisenberg, 1988). Further, sex differences in psychopathology have been linked to sex differences in empathy and the related expressions of empathic concern for the feelings of others (Cohen \& Strayer, 1996). In sum, not only is empathy central to moral development; it also appears to inhibit antisocial behavior and is implicated in sex differences in such behavior.

Sex differences in offending are widely documented. Male offending rates are significantly higher than female rates among both adolescents and adults for all crimes except prostitution, and this gap is greatest for serious, violent crimes against persons and/or 
serious property crime (Kruttschnitt, 1994; Steffensmeier \& Allen, 1996). Moreover, when females do commit serious crimes, they typically result in less financial loss and physical injury than similar offenses committed by males. Evidence also suggests that females who engage in serious offending often have extensive histories of abuse and trauma that are less common among serious male offenders (Chesney-Lind \& Sheldon, 1992, 1998; Daly, 1994; Gilfus, 1992; Widom, 1989). Such patterns remain largely unexplained by mainstream criminological theories (Pollock, 1999; Steffensmeier \& Allen, 1996), but may be linked to female's concern for, and relations with, others.

Mainstream criminological theories implicitly account for sex differences in offending by assuming that females have less exposure to theoretically central risk factors (e.g., deviant peer associations, low-self control, material strains) and more exposure to theoretically central protective factors (e.g., social bonds, social controls) than do their male counterparts. Evidence provides some support for this argument that sex differences in minor forms of offending are, in part, a result of statistically significant differences in exposure to key criminogenic influences (Smith \& Paternoster, 1987). However, such explanations do not entirely account for sex differences in minor offending, and may be even less effective in explaining the more substantial sex differences in serious offending (Chesney-Lind, 1997; Steffensmeier \& Broidy, 2000).

While there is a growing body of empirical work documenting sex differences in risk factors for criminal behavior, less attention has been paid to examining sex differences in the protective factors that may shield females from the lure of offending. In particular, a consideration of the potential role of empathy in inhibiting offending could increase the explanatory power of theoretical models. Moreover, while some evidence suggests that females have a greater tendency toward empathy than males, it is likely that within-sex variations in offending may be related to differences in empathy as well. Empathy is hypothesized to promote prosocial behavior and, as such, high levels of empathy should inhibit serious offending behaviors that involve physical and/or emotional harm to others, independent of sex. The empirical link, among both males and females, between deficits in empathy and various forms of psychopathology, including aggression and conduct disorder, supports this contention (Cohen \& Strayer, 1996; Miller \& Eisenberg, 1988). Notably, while not explicit in mainstream criminological theories, Gottfredson and Hirschi (1990) suggest that a lack of empathy, or what they term insensitivity "to the suffering and needs of others" (1990, p. 89), is an important element of low self-control, thereby increasing the likelihood of criminal behavior. Still, it is low self-control as a risk factor for crime, and not the protective influence of empathy, that is of central interest in their framework.

\section{The Theoretical Link Between Empathy and Sex Differences in Offending}

Theoretical attempts to link empathy and sex differences in offending are rooted in the notion that males and females tend to approach dilemmas and orient their behavior in accordance with distinct priorities. A growing body of empirical work has found that females tend to approach dilemmas from a relational or interpersonal perspective, while males tend to emphasize issues of justice or fairness (Ford \& Lowery, 1986; Gilligan, 1982; Galotti, Kozberg, \& Appleman, 1991). In other words, females tend to prioritize others and are thereby guided by empathic concerns more so than males. Criminologists have argued that such distinctions, which necessarily contribute to behavioral and interactional differences among males and females, are likely implicated in their distinct offending patterns (Morash, 1983; Naffine, 1987; Simpson, 1989; Steffensmeier \& Allen, 1996). 
The contention that empathy may play a key role in our understanding of sex differences in offending is not new. Naffine (1987) critiques mainstream criminology for its depiction of female conformity as an expression of women's passivity, compliance, and/or dependence. She argues that, instead, female conformity is rooted in women's strong sense of morality, a binding conviction in conventional order, and an active concern for the effects of their behavior on those they care about. She argues that it is women's unique ethic of care, not passive compliance, that limits their offending. Steffensmeier and Allen (1996) pick up on this argument, pointing out that sex differences in offending are partly a function of gendered socialization patterns that instill in women, more than men, an acute sensitivity to the needs of others and dependency on the approval and affection of others. As a result, they refrain from criminal acts that might threaten their ties to or hurt others.

Both Morash (1983) and Simpson (1989) make a related argument. Each point out that offending fits more readily into a morality framework that is justice oriented than one that is relation oriented, making empathy a stronger inhibitor of female offending than male offending. The guiding argument is that, because women make decisions regarding law violation in the context of a moral framework that emphasizes empathy, they will not be inclined to break the law for fear of hurting, disappointing, or damaging their relationships with others. While males, too, may be concerned with the effects of their behavior on others, such concerns will be peripheral to their concerns regarding justice and/or fairness. Women's moral calculus, oriented around empathy, provides fewer justifications for and associates more guilt with offending than does the justice-oriented moral calculus of males. The only time women with strong moral convictions may be compelled to break the law is when it serves the express interests of those they care about, thereby outweighing the immorality of breaking the law (Simpson, 1989). Both Morash and Simpson clearly identify sex differences in empathy as potentially central to our understanding of sex differences in offending.

Despite the intuitive appeal of this theoretical argument, there have been few empirical tests of the related propositions, especially among the adolescent populations in which sex differences in empathy and offending emerge. In a recent study, Bush, Mullis, and Mullis (2000) find only limited evidence to support the notion that empathy distinguishes offenders from nonoffenders or males from females. In fact, of the ten dimensions of empathy they examine, only emotional tone distinguishes offenders from nonoffenders and only personal distress distinguishes males from females. However, their research examines empathy differences across offender and sex status separately. As such, it does not clearly test the potential significance of empathy in accounting for sex differences among adolescent offenders. In the current study we examine the role of empathy as both a general protective influence and as a factor in shaping sex differences in offending among adolescents. As such, this study represents an initial test of some of the key propositions emergent from discussions of empathy and juvenile offending.

\section{The Current Study}

In this study we assess the relation between empathic behavior and offending among adolescent males and females by examining differences in emotional and behavioral expressions of empathy between a sample of serious adolescent offenders and a control sample of high school students. While our analyses consider emotional and behavioral expressions of empathy separately, the empathy literature does not lead us, a priori, to anticipate any differences in the manner in which these two components of empathy operate to shape 
offending within or across sex. As such, our hypotheses focus on empathy as a general construct, while our analyses assess these hypotheses in relation to two separate components of this construct—emotional and behavioral empathy.

In particular, we anticipate that, consistent with the literature, our sample will exhibit significant sex differences in empathy. We also hypothesize that empathy inhibits offending, and thereby we expect significant differences in empathy between a serious offender sample and a high school sample. We further hypothesize that sex moderates the relation between empathy and offending such that this relation will be stronger for female adolescents than for male adolescents. This is consistent with the literature, which establishes empathy as more central to the moral decision-making processes of females than of males. In summary, we hypothesize that:

1. Males will exhibit lower levels of empathy than females and juvenile offenders will exhibit lower levels of empathy than high school students.

2. Sex will moderate the relation between empathy and offending status, such that comparing across male and female offender and high school subsamples, female offenders will exhibit the lowest mean empathy scores and female high school students the highest.

\section{METHOD}

\section{Sample}

The data for the present study are derived from self-report questionnaires administered to adolescents attending public high schools in Philadelphia and to adolescents incarcerated in the California Youth Authority (CYA). The high school sample $(n=425)$ ranges in age from 15 to 18 years $(M=16.6, S D=1.1)$ and is fairly evenly split between males and females (43\% male, $57 \%$ female). In addition, the high school sample was fairly ethnically diverse: African American (14\%), Asian (5\%), Hispanic (34\%), White (35\%), and other (12\%).

The juvenile offender sample $(n=232)$ also ranges between 15 and 18 years of age $(M$ $=16.7, S D=.96$ ) with most coming from minority ethnic groups and lower income families. The juveniles were sentenced for a range of committing offenses: $56 \%$ for violent crimes against persons (e.g., murder, rape, robbery, assault), $28 \%$ for property crimes (e.g., burglary, auto theft, receiving stolen property), 5\% for drug related crimes, and $11 \%$ for other crimes (e.g., violation of probation, evading an officer). The average length of incarceration at the CYA was 17 months $(S D=10.7)$, with a minimum of 3 months and a maximum of 60 months. The juveniles who participated in this study are representative of the general CYA population (Steiner, Garcia, \& Matthews, 1997), a population made up of the most serious juvenile offenders in the state. For a detailed description and breakdown of both samples, see Table 1 .

Comparisons of these two samples allow for an exploration of this relation between empathy and offending since individuals incarcerated in the CYA represent serious juvenile offenders, whereas high school students are unlikely to have a serious offense history. While it is likely that the high school sample includes individuals who have engaged in minor forms of delinquency, it is unlikely that a large percentage of these individuals have engaged in the serious violent and property offenses that reflect the committed offenses of those in the CYA sample. Using National Youth Survey data, for example, 
TABLE 1. Demographic Characteristics of Male and Female Participants

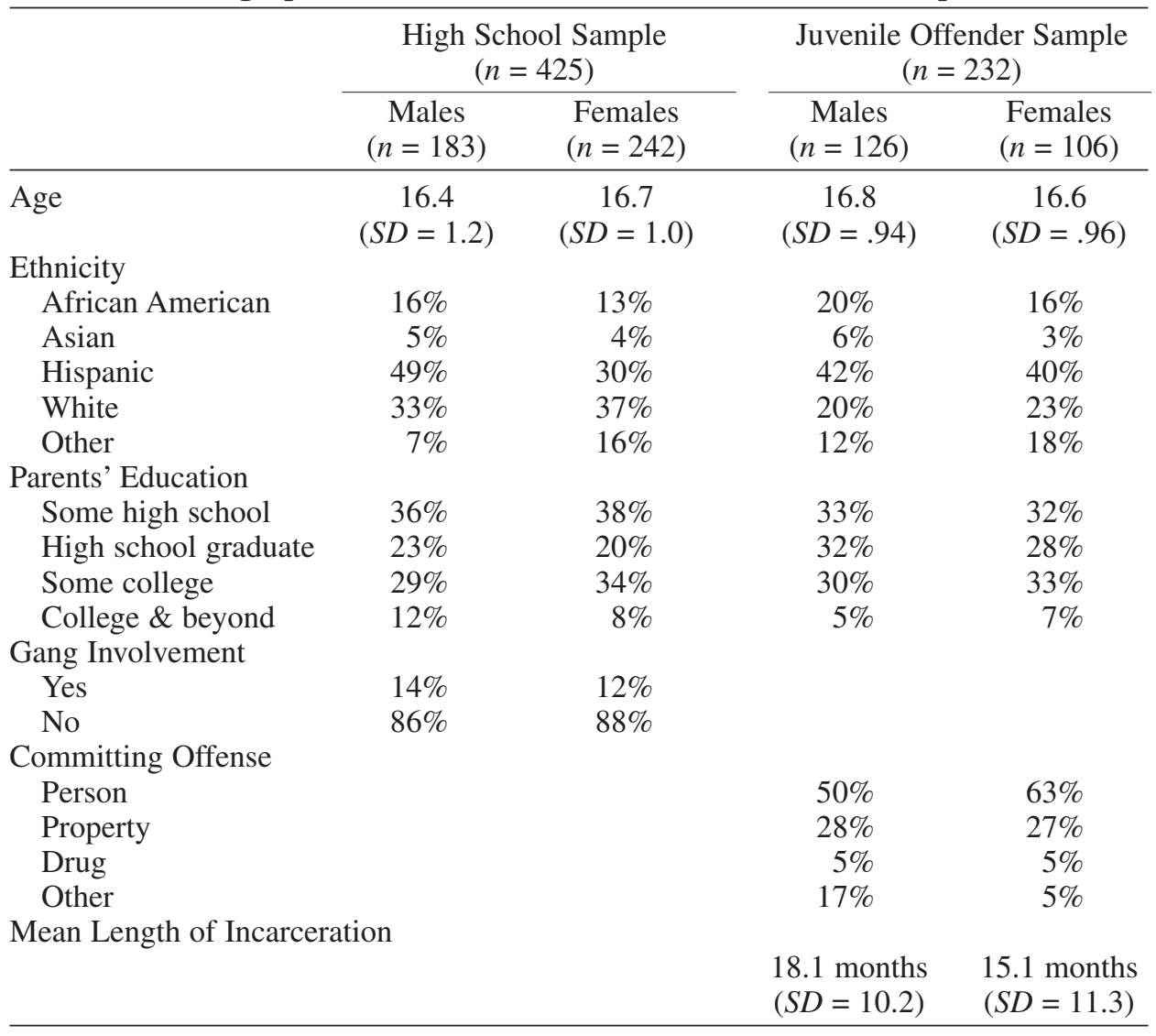

Elliott (1994) reports a prevalence rate of $11 \%$ for serious offending among a representative sample of 16 year olds. To further ensure that serious offenders are not included in the high school sample, we excluded from this sample the $13 \%$ of high school students who reported being in a gang. As such, a binary variable reflecting whether or not a given respondent is in the CYA should be a reliable proxy for serious offending. ${ }^{1}$

\section{Procedure}

Self-report questionnaires were administered at both the high school and the CYA and were originally completed as part of a broader study. A "passive consent" procedure was used to obtain tacit approval from the parents of eighth-, tenth-, and twelfth-grade students, whereby parents were provided an opportunity to withhold consent for their children's participation. In addition to the passive parental consent, active informed consent was obtained from all eligible students. Of the potential participants, $8 \%$ were withheld from the study by their parents and approximately $5 \%$ of the students elected not to participate. Active consent was also obtained from the sample of juveniles interviewed in the CYA. All of the eligible students and offenders were informed about the purpose of the study and asked to complete the questionnaire. Participants were informed that their participation was voluntary and that they could withdraw from the study at any time without penalty. The anonymous selfreport questionnaires were collected during class periods for high school students and in the institution for offenders. 


\section{Measures}

Empathy. Empathy is measured using the Consideration of Others subscale from the Weinberger Adjustment Inventory (WAI; Weinberger \& Schwartz, 1990). This is a sevenitem scale designed to assess the degree to which individuals are attentive to the emotions and general well-being of others. Factor analysis of the seven-item scale was conducted separately for each sample (CYA and high school) and on the combined data set. In each case, factor analysis reveals two factors with eigenvalues greater than one. This suggests that the scale has two distinct dimensions that are identical across offending and nonoffending samples. Focusing on the combined sample, the two factors together explain 58\% of the variance in the factor analysis. The first factor, which accounts for $40 \%$ of variance in the factor analysis, taps the degree to which individuals consider the emotional effect their actions might have on others. The four items that comprise this factor ask individuals to rate the degree to which they think about the feelings of others before acting. For example, "Before I do something, I think about how it will affect the people around me." We label this factor emotional empathy. The second factor, which explains $18 \%$ of the variance, is comprised of three items and taps into the degree to which individuals engage in behaviors for the express benefit of others. For example, "I often go out of my way to do things for other people." We label this factor behavioral empathy. For each of the seven items individuals were asked to rate themselves on a 5-point Likert scale, ranging from almost never to almost always, with higher scores reflecting a greater consideration for others. (See Appendix A for scale items and factor loadings.) Separate emotional and behavioral empathy scales were created by summing scores for each scale item and dividing by the number of items. The emotional empathy scale has an alpha reliability of .64 and the behavioral empathy scale has an alpha reliability of .71. The correlation between these two scales, $.38(p<.05)$, is significant but relatively small, suggesting that the scales, although correlated, represent distinct components of empathy.

\section{Analytic Procedure}

We use two-by-two ANOVA models and t-tests to evaluate the two hypotheses outlined above. First, in order to evaluate hypothesis one, we evaluate main effects ANOVA models for offending status and sex in relation to emotional and behavioral empathy. We evaluate the second hypothesis by using two-by-two ANOVA models for the interaction of sex and offending status in relation to emotional and behavioral empathy. We then conduct post-hoc testing of any interaction effects using $t$-tests to evaluate mean differences in empathy across male and female offender and high school subsamples.

\section{RESULTS}

Hypothesis 1 anticipates sex differences in empathy as well as differences in empathy between juvenile offenders and high school students. Two-by-two ANOVA models comparing emotional and behavioral empathy scores across males and females provide only partial support for this hypothesis. While males exhibit significantly lower behavioral empathy scores than females, there are no significant differences in emotional empathy between males and females. This suggests that, in general, males and females are equally likely to think about how their behavior might affect others, but females are more likely than males to engage in behaviors for the express benefit of others. More consistent with the hypothesis is the finding that mean scores for both emotional and behavioral empathy 
are significantly lower for the offending sample than the high school sample, indicating a more pronounced tendency toward both forms of empathy among high school students in comparison to offenders (Figure 1).

Hypothesis 2 predicts that sex will moderate the relation between offending status and empathy, such that, comparing across all four subsamples, female offenders will exhibit the lowest mean empathy scores and female high school students the highest. Support for this hypothesis would be reflected in a significant interaction between sex and offending status in relation to empathy and $t$-tests establishing significant mean differences in empathy across offender status by sex. Two-by-two ANOVA models examining interaction effects for sex and offender status in relation to empathy support this hypothesis. Consistent with expectations, interaction effects are significant for both behavioral and emotional empathy $(F(3,595)=7.10$ and $F(3,589)=11.36$, respectively) (See Table 2$)$.

Post-hoc testing of the interaction using $t$-tests of mean differences across male and female offender and high school subsamples suggests that, while interaction effects are significant for both types of empathy, the meaning of the interaction term is distinct for the each dimension of empathy. In particular, results of t-tests examining the relation between offending status and empathy separately for males and females are not entirely consistent with the hypothesis. Empathy distinguishes male offenders from their high school counterparts, with the offender sample exhibiting significantly lower levels of both behavioral and emotional empathy. While both dimensions of empathy appear to act as protective factors for males, only emotional empathy appears to have a protective effect for females. Female high school students exhibit significantly higher levels of emotional empathy than do female offenders but, female offenders and high school students exhibit comparable levels of behavioral empathy. Apparently it is female's concern for the emo-

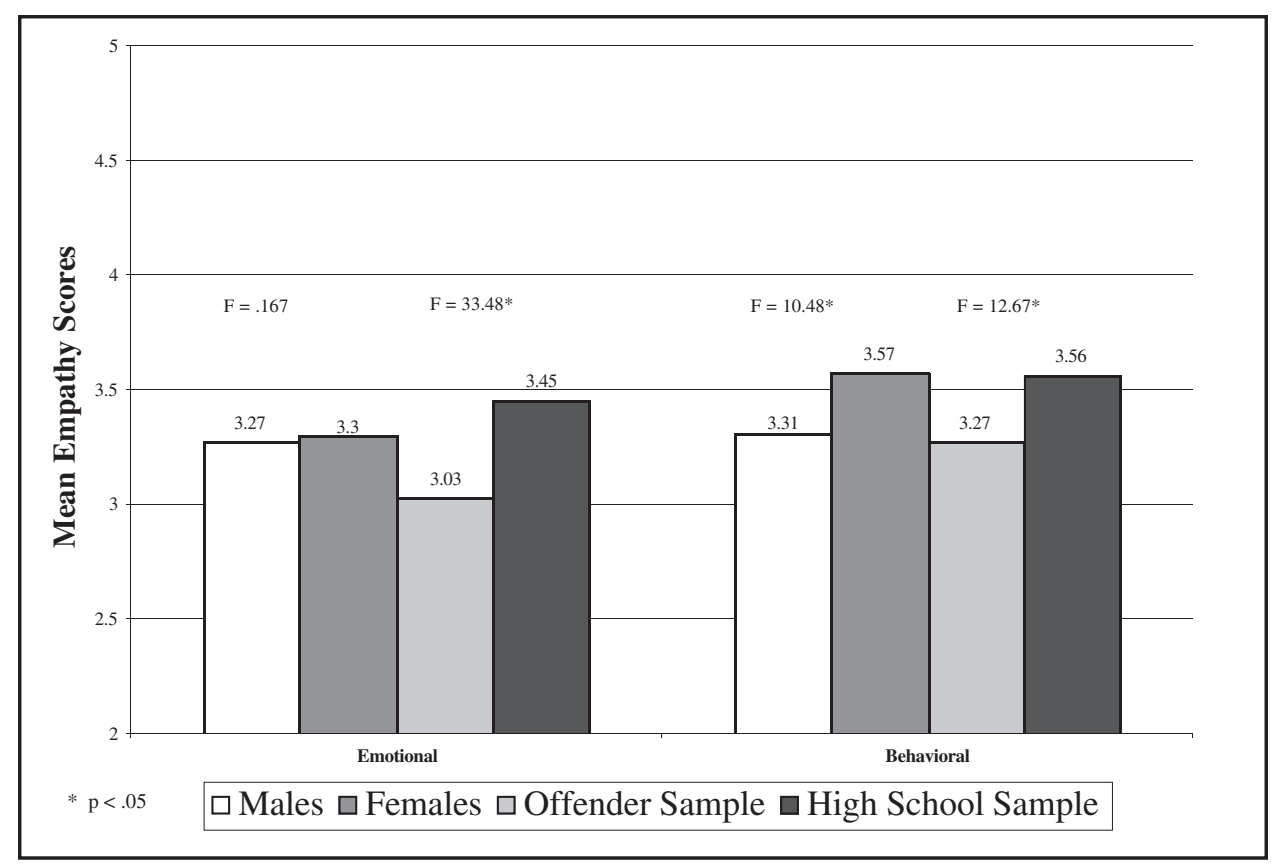

Figure 1. Comparison of mean empathy scores across sex and offending status. 
TABLE 2. Summary of $t$-Test and ANOVA Results Examining Interaction Effects

\begin{tabular}{lccc}
\hline ANOVA & Emotional Empathy & & \multicolumn{2}{c}{ Behavioral Empathy } \\
\cline { 2 - 3 } Means Comparisons & \multicolumn{1}{c}{$M(S D)$} & & \multicolumn{1}{c}{$(S D)$} \\
\hline Sex* Offending $F\left(\eta^{2}\right)$ & $11.36^{*}(.06)$ & & $7.10^{*}(.04)$ \\
Male Offender Sample & $3.07(.08)$ & $3.14(.90)$ \\
Male High School Sample & $3.43(.07)$ & $3.44(.08)$ \\
$t$-statistic & $3.42^{*}$ & $2.69^{*}$ \\
Female Offender Sample & $2.99(.08)$ & $3.42(.11)$ \\
Female High School Sample & $3.46(.06)$ & $3.64(.06)$ \\
$t$-statistic & $4.76^{*}$ & 1.88 \\
\hline
\end{tabular}

$* p \leq .05$.

tional well-being of others as opposed to their tendency to engage in behaviors that benefit others that distinguishes female offenders from their high school counterparts. It may be that behavioral empathy can have both prosocial and antisocial manifestations.

The $t$-tests, then, suggest that the meaning of the significant interaction term sex and offending status in relation to empathy varies across the two forms of empathy evaluated here. For the behavioral empathy the significant sex by offender status interaction reflects the fact that high school females have the highest mean behavioral empathy scores (3.64) and male offenders the lowest (3.14), with mean scores for female offenders and male high school students falling in the middle (3.42 and 3.45 respectively). So although female high school students do report the highest mean levels of behavioral empathy, male offenders exhibit lower mean scores on behavioral empathy than do female offenders. Moreover, mean scores on this variable are more disparate for male offenders compared to their high school counterparts than they are for female offenders compared to their high school counterparts. This further suggests that, for females, behavioral empathy is not strongly correlated with offending status and may lead to both prosocial and antisocial outcomes.

Results for emotional empathy are more consistent with the hypothesis. Here the significant interaction effect reflects the fact that female offenders have the lowest mean emotional empathy scores (2.99) and female high school students the highest (3.46), with mean emotional empathy scores for male offenders and high school students falling somewhere in the middle (3.08 and 3.44 respectively). These results suggest that, with respect to emotional empathy, sex and offender status interact such that mean levels of emotional empathy are more disparate across female offender and high school subsamples than male offender and high school subsamples. That mean differences in self-reported concern for the emotional well-being of others is especially acute when comparing female offender and high school samples suggests that this form of empathy may play an important role in the inhibition of offending among females and its absence may be especially criminogenic.

\section{DISCUSSION}

This study was designed to examine the role of empathy as a protective factor in relation to serious juvenile offending and as an explanation of sex differences in adolescent offending. Consistent with expectations, results indicate that empathy is significantly related to serious offending among adolescents and that there are sex differences in the way in which empathy shapes offending outcomes. In particular, there are significant differences in both 
emotional and behavioral empathy scores between offenders and high school students. However, the role of empathy in explaining sex differences in serious adolescent offending is more complex.

In particular, results reveal significant sex differences in behavioral empathy for all adolescents in the sample, independent of offending status. In general, adolescent females in this sample, regardless of offending status, are significantly more likely to engage in behaviors reflecting concern for other people than are males. On the other hand, we find no significant sex differences in emotional empathy among offenders or high school students. Regardless of offending status, males and females appear equally likely to think about the feelings of others before acting. Interestingly, though, while females have significantly higher behavioral empathy scores than those of males, behavioral empathy distinguishes male offenders and high school students, but not females. On the other hand, there are significant differences in emotional empathy between female offenders and female high school students. Differences in emotional empathy are significant among male offenders and male high school students as well. The ANOVA results examining interaction effects further tease out these relationships, suggesting that, especially for adolescent females, deficits in emotional empathy are more criminogenic than deficits in behavioral empathy, despite the fact that there appear to be notable sex differences in behavioral and not emotional empathy.

While this study has important implications regarding the influence of empathy on offending behavior and sex differences in offending, there are some limitations that qualify the findings reported here. The samples used for these analyses, while demographically similar, are geographically distinct. The offending sample was drawn from a juvenile facility in California, while the high school sample was drawn from a high school near Philadelphia. Accordingly, some of the differences between offenders and high school students may be attributable to unidentified influences that vary across these distinct geographical environments. Further, the offending sample represents a group of predominantly violent, repeat juvenile offenders. It is thus possible that empathy differences between offenders and high school students reported here are exaggerated. It is also notable that there are no comparable measures of offending across our two samples, precluding any analyses that treat empathy as the independent rather than the dependent variable in relation to offending. Future research should examine the influence of empathy on various measures of offending, with a more diverse sample of offenders and nonoffenders.

Another important limitation is our inability to convincingly establish the causal order of the empathy/offending relation with this data. While our data indicate a clear correlation between empathy and offending, it is conceivable that what we have uncovered here is an incapacitation effect. It may be that the CYA sample experienced a decline in empathy as a function of their incarceration as opposed to their lesser empathy explaining their ultimate admission to CYA. Our data do contain a measure reflecting length of incarceration and it is notable here that there is no significant correlation between length of incarceration and either of the empathy measures among the incarcerated sample. This would suggest that the relation between empathy and offending is independent of incarceration experiences. Future research needs to provide a better test of the hypothesized causal relation between empathy and offending by testing the influence of empathy on later offending via longitudinal data analysis.

Despite these limitations, our results have important implications for future theoretical and empirical work examining the relation between empathy and offending. The results provide some support for our general expectation that empathy differences would help to 
account for sex differences in serious offending. Focusing on emotional empathy, there is a significant interaction between sex and offending status with female high school students reporting the highest mean score and female offenders reporting the lowest mean score. Hence, there are greater differences in emotional empathy between offending and nonoffending females than males. This is consistent with the argument that females should require greater empathy deficits than males before engaging in serious offending. That this does not hold for behavioral empathy as well is, however, notable. Our measure of behavioral empathy reflects a tendency to do things for other people, whereas our measure of emotional empathy reflects a tendency to think about how one's own actions might make another person feel. Serious offending may be more inconsistent with the latter than the former. In fact, research examining motivations for serious offending among adolescent males and females indicates some overlap (i.e., money, excitement, peer status/reputation) but also suggests that, for females, serious offending is oftentimes motivated by a concern for others (Baskin \& Sommers, 1998). A woman may, for example, assault a husband or boyfriend because she believes he is a threat to her child. A female may involve herself in the drug trade on the behest of her male partner. In other words, women, more so than men, often engage in crime to protect relationships and emotional commitments (Gilfus, 1992; Steffensmeier \& Broidy, 2000).

This argument is consistent with the contentions of Morash (1983) and Simpson (1989) that while empathy is generally a protective factor for females, it can be criminogenic if accompanied by the perception that breaking the law would somehow benefit those they care about. Both suggest that, when females do break the law, it is often for the express benefit of others and, as such, a function of their empathic moral orientation. In other words, behavioral empathy may be manifest in either prosocial or antisocial behaviors. Hence, sex-based differences in motivations for serious offending may be responsible for the observation that deficits in emotional, but not behavioral empathy distinguish female offenders from female nonoffenders, while for males deficits in both forms of empathy distinguish offenders from nonoffenders. In this sample, all females (offenders and high school students) make a concerted effort to engage in behaviors that will benefit others, but offenders are less inclined to think about the emotional impact of their actions on others. This could suggest that, while adolescent female offenders are genuinely concerned with how their behavior impacts others, they are less able than their nonoffending counterparts to cognitively evaluate the emotional impact of that behavior on others.

Our findings have some clinical implications, especially for those clinicians providing care and consultation to incarcerated youth. First, the fact that empathy is low among juvenile offending populations suggests that treatment should focus on increasing youth's ability to feel for others, and to behave in accordance with these feelings. In addition, since deficits in emotional empathy appear to be more strongly correlated with offending than deficits in behavioral empathy, such treatments should emphasize building the cognitive ability to recognize and respond to the emotions of others (Tremblay \& Craig, 1995). Second, subtle differences in the relation between empathy and offending across male and female samples indicate that the lack of empathy among adolescent female offenders in particular may interfere with the ability of these girls to benefit from the rehabilitative programs offered by the juvenile justice system. Since the majority of programs are male oriented (reflective of the fact that males comprise the majority of incarcerated youth), treatment programs may not be addressing the needs of these girls. As a result, the rehabilitative goal of treatment may not be met for young female offenders. By improving our understanding of the trajectories that lead to delinquency among males and females, and of the ways 
that empathy influences these trajectories, this study lays the foundation for the development of more effective, gender appropriate intervention strategies, and provides a scientific foundation upon which policymakers can base debates over the proper treatment of juvenile offenders. In addition, it will allow the generation of more specific hypotheses regarding the nature of both male and female offending to be explored in larger-scale longitudinal investigations.

In summary, our findings suggest that the relation between empathy and offending warrants further attention. Significant differences in emotional and behavioral empathy across offending and nonoffending samples were observed, suggesting that empathy may be more central to explanations of offending than current theories indicate. Future research should explore in further detail the differences between emotional and behavioral empathy and the implications of these differences for the offending patterns of males and females. It is possible that the influence of emotional and behavioral empathy on offending is conditioned by motivations for offending. Future research should explore whether behavioral empathy increases the likelihood of criminal actions that reflect altruistic motives, such as the commitment of forgery or fraud in the interest of feeding one's children, or assaults and homicides committed in the interest of saving oneself or one's child from abuse. Moreover, given that serious offending by females is often precipitated by a history of abuse and or trauma, future work should explore the influence of abuse and trauma on the development of empathy and its expression as concern for the emotions of others. It may be that empathy moderates the relation between abuse/trauma and serious offending among females.

\section{NOTES}

1. We recognize that the distinction between the CYA sample and the high school sample may not perfectly reflect the offending/nonoffending distinction we are attributing to it. Nonetheless, the seriousness of the offenses necessary to warrant admission to the CYA clearly designate the CYA sample as unquestionably delinquent, while studies of high school samples indicate that incidences of serious delinquent involvement are limited to a very small percentage of high school children. As such, we would argue that such a sample provides a reasonable basis for an initial test of the relation between empathy and offending.

\section{REFERENCES}

Baskin, D. R., \& Sommers, I. B. (1998). Casualties of community disorder. Boulder, CO: Westview Press.

Batson, C. D., \& Coke, J. S. (1981). Empathy: A source of altruistic motivation for helping? In J. P. Rushton \& R. M. Sorrentino (Eds.), Altruism and helping behavior: Social, personality and developmental perspectives (pp. 167-211). Hillsdale, HJ: Erlbaum.

Bush, C. A., Mullis, R. L., \& Mullis, A. K. (2000). Differences in empathy between offender and non-offender youth. Journal of Youth and Adolescence, 29, 467-480.

Chesney-Lind, M. (1997). The female offender: Girls, women and crime. Thousand Oaks, CA: Sage.

Chesney-Lind, M., \& Sheldon, R. (1992). Girls, delinquency, and juvenile justice. Pacific Grove, CA: Brooks/Cole.

Chesney-Lind, M., \& Sheldon, R. (1998). Girls, delinquency, and juvenile justice (2nd ed.). Belmont, CA: Wadsworth. 
Cohen, D., \& Strayer, J. (1996). Empathy in conduct disordered and comparison youth. Developmental Psychology, 32, 988-998.

Daly, K. (1994). Gender, crime, and punishment. New Haven, CT: Yale University Press.

Eisenberg, N. (2000). Emotion, regulation, and moral development. Annual Review of Psychology, 51, 665-697.

Eisenberg, N., \& Miller, P. A. (1987). The relation of empathy to prosocial and related behaviors. Psychological Bulletin, 101, 91-119.

Elliott, D. (1994). Serious violent offenders: Onset, developmental course, and termination. Criminology, 32, 1-22.

Feshbach, N. D. (1975). Empathy in children: Some theoretical and empirical considerations. The Counseling Psychologist, 4, 25-30.

Ford, M., \& Lowery, C. (1986). Gender differences in moral reasoning: A comparison of the justice and care orientations. Journal of Personality and Social Psychology, 50, 777-783.

Galotti, K., Kozberg, S., \& Appleman, D. (1991). Younger and older adolescents' thinking about commitments. Journal of Experimental Child Psychology, 50, 324-339.

Gilfus, M. (1992). From victims to survivors to offenders: Women's routes to entry and immersion into street crime. Women and Criminal Justice, 4, 63-89.

Gilligan, C. (1982). In a different voice: Psychological theory and women's development. Cambridge, MA: Harvard University Press.

Gottfredson, M. R., \& Hirschi, T. (1990). A general theory of crime. Stanford, CA: Stanford University Press.

Hoffman, M. L. (1977). Moral internalization: Current theory and research. In L. Berkowitz (Ed.), Advances in experimental social psychology (Vol. 10, pp. 85-133). New York: Academic Press.

Kohlberg, L. (1976). Moral stages and moralization: The cognitive-developmental approach. In T. Lickona (Ed.), Moral development and behavior: Theory, research, and social issues. New York: Holt, Rinehart and Winston.

Kruttschnitt, C. (1994). Gender and interpersonal violence. In J. Roth \& A. Reiss (Eds.), Understanding and preventing violence: Social influences (Vol. 3, pp. 295-378). Washington, DC: National Academy of Sciences.

Mehrabian, A., \& Epstein, N. A. (1972). A measure of emotional empathy. Journal of Personality, 40, 523-543.

Miller, P. A., \& Eisenberg, N. (1988). The relation of empathy to aggression and externalizing/antisocial behavior. Psychological Bulletin, 3, 324-344.

Morash, M. (1983). An explanation of juvenile delinquency: The integration of moral reasoning theory and sociological knowledge. In W. S. Laufer \& J. M. Day (Eds.), Personality theory, moral development, and criminal behavior (pp. 385-414). Lexington, MA: Lexington Books.

Naffine, N. (1987). Female crime: The construction of women in criminology. Boston: Allen and Unwin.

Pollock, J. M. (1999). Criminal women. Cincinnati, OH: Anderson Publishing Co.

Simpson, S. (1989). Feminist theory, crime and justice. Criminology, 27, 605-631.

Smith, D, \& Paternoster, R. (1987). The gender gap in theories of deviance: Issues and evidence. Journal of Research in Crime and Delinquency, 24, 140-172.

Steffensmeier, D., \& Allen, E. (1996). Gender and crime: Toward a gendered theory of female offending. Annual Review of Sociology, 22, 459-487.

Steffensmeier, D. \& Broidy, L. M. (2000). Explaining female offending. In L. Goodstein (Ed.), Women, crime, and criminal justice: Contemporary issues. Los Angeles: Roxbury Press.

Steiner, H., Garcia, I., \& Matthews, A. (1997). Posttraumatic stress disorder in incarcerated juvenile delinquents. Journal of the American Academy of Child and Adolescent Psychiatry, 36, 357-365.

Tremblay, R. E., \& Craig, W. M. (1995). Developmental crime prevention. In M. Tonry \& D. P. Farrington (Eds.), Strategic approaches to crime prevention: Building a safer society. University of Chicago Press. 
Underwood, B., \& Moore, B. (1982). Perspective-taking and altruism. Psychological Bulletin, 91, $143-173$.

Weinberger, D. A., \& Schwartz, G. E. (1990). Distress and restraint as superordinate dimensions of self-reported adjustment: A typological perspective. Journal of Personality, 58, 381-417.

Widom, C. (1989). Child abuse, neglect, and violent criminal behavior. Criminology, 27, 251-271.

Acknowledgment. Preparation of this manuscript was supported by funding to Dr. Cauffman from the Stanford Center on Adolescence and the John D. and Catherine T. MacArthur Foundation Network on Adolescent Development and Juvenile Justice. Dr. Cauffman would like to thank the California Youth Authority, in particular Dr. Saeed Behshid, Elaine Duxbury, Dr. Rudy Haapanen, and Dr. Wes Ingram for coordinating and executing this study. The authors are especially grateful to Kevin Krasnow, Wendy Lovejoy, and Renee Pavelski for their assistance in the collection and coding of the data.

Offprints. Requests for offprints should be directed to Lisa Broidy, PhD, Department of Sociology, University of New Mexico, 1915 Roma NE, Albuquerque, NM 87131-1166. E-mail: lbroidy@unm.edu

\section{APPENDIX A. Item Factor Loadings, Eigenvalues, and Alpha Reliability- Scores for Empathy Scales}

Items

Emotional Empathy

Behavior Empathy (Factor One*) (Factor Two)

Before I do something, I think about how it it will affect the people around me.

0.792

I make sure that doing what I want will not cause problems for other people.

I think about other people's feelings before I do something they might not like.

I try very hard not to hurt other people's feelings. $\quad 0.512$

I often go out of my way to do things for other people.

0.009

Doing things to help other people is more important to me than almost anything else. $\quad 0.006$

I enjoy doing things for other people, even when I don't receive anything in return.

Initial Eigenvalue

0.384

Scale Alpha

*Factors computed using Principal Axis Factoring (PAF) with Varimax Rotation. Factor loadings reported for combined offending and nonoffending samples, but available for offending and nonoffending samples separately upon request. 